\title{
Influence of temperature on seed germination response of fennel
}

\begin{abstract}
In order to determine the effect of temperature on germination response of fennel seeds, in Petri-dishes, seeds of 3 varieties (Hamedan, Malayer and Isfahan) were exposed to 6 constant temperatures $\left(10,15,20,25,30\right.$ and $\left.35^{\circ} \mathrm{C}\right)$. Results indicated that the temperature had a significant effect on the maximum germination percentage, germination uniformity, germination rate, and time to $5,10,50,90$ and $95 \%$ germination, while insignificant effect of variety and interacted effect of temperature and variety was observed. Among three non-linear regression models used in assessment (segmented, dent-like and beta), the dent-like model was found to be appropriate. Basic temperature of seed germination for the three tested varieties was estimated at $5^{\circ} \mathrm{C}$. Lower optimum temperatures of seed germination for Hamedan, Malayer and Isfahan varieties were $12.53,12.75$ and $13.45^{\circ} \mathrm{C}$, while upper optimum temperatures were $25.00,32.81$ and $33.56^{\circ} \mathrm{C}$, respectively. Ceiling temperatures were estimated at $40.12,42.00$ and $35.57^{\circ} \mathrm{C}$, respectively. Biological time for $50 \%$ seed germination for Hamedan, Malayer and Isfahan varieties was estimated at 165.5, 168.4 and 158.3 hours, respectively.
\end{abstract}

Keywords: fennel, cardinal temperature, non-linear regression models, segmented model, beta model, dent-like model, germination biological time
Volume I Issue 5 - 2014

\author{
Zohreh Heidari,' Behnam Kamkar, Jafar \\ Masoud Sinaki' \\ 'Agronomy Department, Damghan branch, Islamic Azad \\ University, Damghan, Iran \\ ${ }^{2}$ Department of Agronomy, Gorgan University of Agricultural \\ Sciences and Natural Resources (GUASNR), Iran
}

\begin{abstract}
Correspondence: Behnam Kamkar, Department of Agronomy, Gorgan University of Agricultural Sciences and Natural Resources (GUASNR), Faculty of Plant Production, Basij Square, Pardis No. 2, 49189-43464, Gorgan, Iran, Tel +98-17-34427060, Fax+98-17-24420438, Email behnamkamkar@yahoo.com
\end{abstract}

Received: September 16, 2014 | Published: December 13, 2014
Abbreviations: MGP, maximum germination percentage; $\mathrm{GU}$, germination uniformity; GR, germination rate; RMSE, root mean square of errors; $\mathrm{CV}$, coefficient of variation; $\mathrm{R}^{2}$, coefficient of determination; $\mathrm{T}_{\mathrm{b}}$, base temperature; $\mathrm{T}_{\mathrm{o}}$, optimum temperature; $\mathrm{T}_{\mathrm{ol}}$, lower limit of optimum Temperature; $\mathrm{T}_{\mathrm{o} 2}$, upper limit of optimum temperature; $T_{c}$, ceiling temperature; Fo, biological time

\section{Introduction}

Fennel [Foeniculum vulgare Mill L] is one of the important medicinal and spice plants of the world ${ }^{1}$ and has become one the most economical medicinal plants in the Mediterranean region. ${ }^{2}$ Fennel is traditionally used for medicinal and culinary purposes. The entire plant is valuable in the medicinal industry; its enlarged base is used as a vegetable; its leaves are used for culinary purposes and its seeds as a spice and for essential oil extraction. The flowers and leaves are also used to make yellow and brown dyes. ${ }^{3}$

At present, growing medicinal plants is an important sector in agriculture and is the main source of extracting and producing raw materials for manufacturing current drugs. That is why in most developed countries research centers have been established specifically for medicinal plants. These centers identify and introduce numerous active ingredients in plants, together with their desirable effects. ${ }^{4}$

Different definitions, with great similarities, have been offered for seed germination. The stage in which the embryo ruptures the seed coat after absorbing water, and during which the plumule and the radicle emerge, is called germination. ${ }^{5}$ Seed germination is considered one of the sensitive stages in the life cycle of plants because it plays a major role in determining the final plant density. Factors such as gene control, seed size, viability, depth of planting, soil moisture, oxygen concentration, and temperature, influence on germination and seedling emergence. ${ }^{6-8}$
Temperature is the most important driving force influencing crop development rate. ${ }^{9}$ The effects of temperature on plant development are the basis for models used in predicting germination timing. ${ }^{10}$ Temperature and moisture are among the very important environmental factors in the germination of non-dormant seeds. ${ }^{11,12}$ These two factors, singly or in combination, can influence on germination percentage and rate. ${ }^{13,14}$

Plants have base or minimum, optimum, and ceiling temperatures for seed germination. The minimum or base temperature is the lowest temperature which seeds can be germinated. The optimum temperature is the temperature which seeds ratch its highest germination rate, and the maximum or ceiling temperature is the temperature above which seeds cannot germinate. ${ }^{15,16}$ Use of cardinal temperatures makes it possible to estimate geographical limitations and select the suitable time before planting seeds. ${ }^{16}$

Cardinal temperatures of germination usually depend on the range of adaptability of the related species and insure the coincidence of germination with desirable conditions for the following stages of development. ${ }^{12}$ Seed germination of any plant takes place in a specific range of temperatures called the cardinal temperatures. ${ }^{17}$ In this range, there are minimum, optimum, and maximum temperatures that have applications in presenting models for predicting germination. ${ }^{16}$ Germination rate increases with rises in temperature up to the optimum one and declines at temperatures exceeding it. ${ }^{18}$ Plant growth rate increases with rises in temperature from the base to the optimum temperatures and declines at temperatures between the optimum and the ceiling ones. ${ }^{19}$ Seeds germinate in a wide range of temperatures, but their maximum germination considerably changes at the upper and lower thresholds of this range. The temperature range within which germination is at its maximum varies depending on species and seed quality. ${ }^{20}$ 
Seeds of each plant type need a minimum temperature for germination. Sometimes, some seed types germinate at low temperatures such as zero or close to zero degrees, but these temperatures prevent germination of other seed types. ${ }^{21}$ For most plants, the optimum and maximum germination temperatures are 1530 and $30-40^{\circ} \mathrm{C}$, respectively. ${ }^{22}$

There are numerous reports suggesting germination percentage and rate increase up to a point with rises in temperature. ${ }^{23,24}$ Temperature can influence on germination percentage and rate through affecting seed deterioration by reducing seed dormancy and through all other germination processes. ${ }^{25}$ Cardinal temperature variables are usually evaluated in the normal or lognormal distribution of CT variables. ${ }^{26}$

Various types of mathematical functions have been used to describe relationships between germination rate and temperature. ${ }^{6,19}$ The advantage of these functions is that their parameters refer to biological concepts such as cardinal temperatures, intrinsic germination rate, and emergence.

Non-linear regression models have been used for quantifying germination responses and plant seed germination against temperature..$^{27-30}$ Mwale $^{27}$ used non-linear regression models in sunflower, Ramin ${ }^{16}$ in Persian leek, Ellis ${ }^{28}$ in peas, and Jame et al., ${ }^{29}$ in wheat. Ghaderi-Far ${ }^{31}$ used segmented models in subterranean clover. Kamkar, ${ }^{32}$ in their study on poppy, used non-linear regression models and introduced the segmented model as the superior model in predicting the germination rate. Kamkar, ${ }^{9,33}$ also used segmented and logistic models to determine cardinal temperatures of germination in 3 millet varieties and emergence in wheat cv. "Tajan". Ghaderi-Far ${ }^{4}$ also evaluated six non-linear regression models, including the dentlike, segmented, beta, curvilinear, quadratic and cubic models in the 3 medicinal plants, pumpkin, brago and black cumin, and concluded that the dent-like model described germination responses to temperature in these plants better than the rest. Moreover, Nozari-Nejad ${ }^{34}$ studied germination responses of wheat to temperature and moisture using non-linear regression models and selected the dent-like model as the superior one. Soltani ${ }^{19}$ used the beta, segmented, and dent-like models in modeling emergence in peas at various temperatures and planting depths and recommended the dent-like model as the superior one.

Given the ever-increasing importance of medical plants in foodstuff and in providing medicines needed by people, completion and compilation of information on the ecophysiological behaviors of these plants is a necessity, while basic information specially ecological requirements of these crops has not studied well and we are faced by lack of these data in those researches which are parameter-based such as crop modeling or GIS-oriented researches. This investigation was conducted with the purposes of determining the effect of temperature on seed germination response of fennel and of finding the cardinal temperatures of germination.

\section{Materials and methods}

This investigation was conducted at the laboratory of Seed Research of Gorgan University of Agriculture and Natural Resources in 2012. Three varieties of fennel (Hamedan, Malayer, and Isfahan) were concerned to determine seed germination at 6 levels of temperature $\left(10,15,20,25,30\right.$ and $\left.35^{\circ} \mathrm{C}\right)$. In Petri dishes $(9-\mathrm{cm}$ diameter), the experiment was designed as a randomized complete block design with 4 replications using a factorial arrangement of treatments. Incubators with the accuracy of 0.5 degree centigrade were used for the temperature treatments. Each experimental unit (Petri dish) consisted 50 fennel seeds seeded on top of 2 sheets of filter paper and covered by a single sheet of filter paper. The experiment was carried out in dark condition, as all Petri dishes were covered with aluminium foil, except when counting was doing. During the experiment, distilled water was added when needed in the way that filter papers were always wetted without seeds submergence. This was done in a daily time step. Subsequently, depending on the temperature used, the numbers of germinated seeds at different time intervals were counted. Obviously, this interval will be shorter for temperatures closer to the optimum one. At each interval, the germinated seeds were removed. The criterion for germination was a radical emergence of 2 millimeters or more. Counting was stopped when no seeds germinated within 48 hours, or when all the seeds had germinated. Each time the germinated seeds were counted, the exact time of counting was recorded. ${ }^{32}$

The GS-2011 software ${ }^{35}$ was used to extract the deciles of germinations. The software fitted seed germination data from these temperature regimes to the logistic function and performed the necessary calculations through interpolation. Moreover, germination rate (per hour) was determined by using formula $1:{ }^{19} G R=1 D 50 \ldots . .(1)$

In the above formula, GR is the germination rate and D50 the time it takes for 50 percent of the seeds to germinate. In this study, 3 temperature functions were compared to describe changes in germination rate against temperature. These functions were:

1. The Beta function, shown by the abbreviation B, is as follows: ${ }^{19}$

$$
f(T)=[(T-T b T o-T b) *(T c-T T c-T b)(T c-T o T o-T b)] \alpha f o \ldots \ldots .(2)
$$

The Dent-like function, shown by the abbreviation D, is as follows: ${ }^{36}$

$$
\begin{aligned}
& f(T)=(T-T b)(T o 1-T b) \text { if } T b<T \leq T o 1 \\
& f(T)=(T-T b)(T o 1-T b) \text { if } T o 2<T \leq T c \text {.....(3) } \\
& f(T)=1 \text { if } T o 1<T \leq T o 2 \\
& f(T)=0 \text { if } T \leq T b \text { or } T \geq T c
\end{aligned}
$$

2. The Segmented function, shown by the abbreviation $\mathrm{S}$, is as follows: ${ }^{37}$

$$
\begin{aligned}
& f(T)=(T-T b)(T o-T b) \text { if } T b<T<T o \\
& f(T)=[1-(T-T o)(T c-T o)] \text { if } T o<T<T c \ldots . . \\
& f(T)=0 \text { if } T \leq T b \text { or } T \geq T c
\end{aligned}
$$

In the above function, $\mathrm{T}_{\mathrm{b}}$ is the base temperature, $\mathrm{T}_{\mathrm{ol}}$ the lower limit of optimum temperature, $\mathrm{T}_{\mathrm{o} 2}$ the upper limit of optimum temperature, $\mathrm{T}_{\mathrm{o}}$ the optimum temperature, $\mathrm{T}_{\mathrm{c}}$ the ceiling temperature, Fo the biologic time, "a" a constant coefficient, and $\mathrm{T}$ the average daily temperature (the temperature at which the experiment was conducted). Parameters of each model were estimated by a method of iterative optimization with the help of the PROC NLIN procedure of the SAS software. ${ }^{38}$ In this method of iterative optimization, every time the initial values of the parameters are entered, the final value is estimated by the leastsquares method. Initial values are changed until the best estimate of the paramters is obtained. The root mean square of errors (RMSE) of germination time, the coefficient of determination $\left(\mathrm{R}^{2}\right)$, the correlation coefficient (r), the simple linear regression coefficients $a$ and $b$, and the relationship between the observed and the predicted germination 
rates were used to select the superior model from among the employed methods.

The higher coefficient of determination $\left(\mathrm{R}^{2}\right)$ is the higher percentage of changes in germination rate explained by the model. Coefficients "a" and "b" represent the degree of deviation of the regression line from the origin of coordinates and the bias of the regression line from the 1:1 line, respectively. The SAS software determined the numerical values of coefficients "a" and "b." Significance of coefficient "a" was investigated by SAS and that of coefficient "b" by determining confidence limits. If coefficient " $a$ " is significant, it means that the $y$-intercept of the regression line and the y-intercept of the 1:1 line do not coincide. If coefficient " $b$ " is significant, it means that the slopes of the regression line and that of the 1:1 line are different and that the regression line is biased, in relation to the $1: 1$ line. ${ }^{39}$ The less the points are scattered around the 1:1 line, the more efficient the model is. Given these criteria, the superior model was used to determine the cardinal germination temperatures for describing germination rates of various fennel varieties.

\section{Results and discussion}

Data presented in Table 1 assessed by the mean squares of maximum germination percentage (MGP), germination uniformity $(\mathrm{GU})$, germination rate $(\mathrm{GR})$, the time of reaching $5 \%\left(\mathrm{D}_{5}\right), 10 \%\left(\mathrm{D}_{10}\right)$, $50 \%\left(D_{50}\right), 90 \%\left(D_{90}\right)$, and $95 \%\left(D_{95}\right)$ germination indicated that the effects of temperature were significant at the one percent probability level. However, insignificant effects based on variety and the mutual effects of variety and temperature were observed. Since temperature has considerable effects on germination characteristics including the start, the percentage, and the rate of germination, it is, therefore, the most critical factor in the determination of success or failure of plant establishment. ${ }^{24}$ The reduction in germination percentage and rate at undesirable temperatures can be attributed to the reduction or inhibition of enzymatic activity. ${ }^{40}$ Moreover, another mechanism for this reduction is reduced metabolic efficiency at temperatures higher than optimum ${ }^{41}$ (Table 1).

The beta and the segmented models estimate the base, the optimum, and the ceiling temperatures and the biological time, while the dentlike model estimates the range of optimum temperatures (from the lower limit of optimum temperature to the upper limit of optimum temperature). The criteria used in comparing different models for selecting the superior one to be used in describing germination responses to temperature in various varieties of fennel include root mean square of error (RMSE), the coefficient of determination $\left(\mathrm{R}^{2}\right)$, the regression coefficients " $a$ " and " $b$ ", and the relationship between the observed germination rate and the predicted one (Table 2).

\section{Results obtained from comparison of these criteria are as follow:}

In the Hamedan variety, the " $b$ " coefficient (the bias of the regression line from the 1:1 line) was not significant in any of the 3 models and its value in the segmented model (0.95) was closer to one compared to the other 2 models. Moreover, the "a" coefficient (the degree of deviation of the regression line from the origin of the coordinates) was not significant in any of the 3 models and its value in the segmented model $(0.0001)$ was closer to zero compared to the other 2 models (Table 2). The coefficient of determination $\left(\mathrm{R}^{2}\right)$ in the dent-like model $(99 \%)$ was higher, the root of mean square of error (RMSE) and the coefficient of variation (CV) (0.0003 and 11.36, respectively) were lower (Table 2), and the points around the 1:1 line were less scattered compared to the other 2 models (Figure 1). Considering the above points (although the numerical values of "a" and "b" coefficients in the segmented model were better compared to the other 2 models), the difference between the values of these 2 parameters in these 2 models and that of the dent-like model can be ignored. Moreover, the RMSE and $\mathrm{CV}$ and the scattering of the points around the 1:1 line in the dentlike model were less, and the coefficient of determination was higher, compared to the other 2 models. Therefore, the dent-like model was selected as the superior model for the Hamedan variety and was used in later stages to determine the cardinal temperatures of germination in this variety (Figure 1).

In the Malayer variety, the "b" coefficient (the bias of the regression line from the 1:1 line) in none of the 3 models was significant and its value $(0.90)$ in the dent-like model was closer to one compared to the other 2 models. Moreover, the "a" coefficient (the degree of deviation of the regression line from the origin of the coordinates) was not significant in any of the 3 models and its value in the dent-like model $(0.0005)$ was closer to zero compared to the other 2 models (Table 3 ). The coefficient of determination $\left(\mathrm{R}^{2}\right)$ in the dent-like and beta models (99\%) was higher than that of the segmented one (Table 2). The RMSE and the CV in the dent-like model (0.0002 and 5.34, respectively) were lower compared to the other 2 models (Table 2 ). The points were less scattered around the 1:1 line in the dent-like model compared to the other 2 models (Table 2). Considering the above points, and since the RSME, the CV, and the scattering of the points around the 1:1 line were lower and the $\left(\mathrm{R}^{2}\right)$ was higher in the dent-like model, it was selected as the superior model for the Malayer variety and was used in later stages to determine the cardinal temperatures of germination for this variety (Figure 2).

In the Isfahan variety, the " $b$ " coefficient (the bias of the regression line from the 1:1 line) in none of the 3 models was significant and its value in the dent-like model (0.92) was closer to one compared to the other 2 methods. Moreover, the "a" coefficient (the degree of deviation of the regression line from the origin of the coordinates) in the beta and dent-like models was not significant but it was significant in the segmented model at the 5 percent probability level. The value of the "a" coefficient in the dent-like model $(0.0004)$ was closer to zero, and the coefficient of determination $\left(\mathrm{R}^{2}\right)(99 \%)$, the RMSE and the CV (0.0005 and 6.32, respectively) (Table 2$)$ and the scattering of the points around the 1:1 line were lower compared to the other 2 models (Table 2). Considering the above points, and because the "a" coefficient in the segmented model was significant, this model was eliminated in selecting the superior model for the Isfahan variety. Since the values of the RMSE, the CV, the degree of scattering of the points around the 1:1 line, and the $\left(\mathrm{R}^{2}\right)$ were higher in the dent-like model compared to the beta model, in the Isfahan variety too the dentlike model was selected as the superior model and was later used in determining the cardinal temperatures in this variety.

Since the dent-like model was selected as the superior model for the three tested varieties, its parameters including the base, the lower limit of optimum, the upper limit of optimum, and the ceiling temperatures were determined for the 3 varieties. Based on the obtained result:

For the three tested varieties of Hamedan, Malayer, and Isfahan, the base temperature was estimated to be $5^{\circ} \mathrm{C}$, and the lower and the upper limits of optimum temperature for the Hamedan, Malayer, and Isfahan varieties were estimated at 12.53 and $25.00 ; 12.75$ and 32.81 , and 13.45 and $33.56^{\circ} \mathrm{C}$ respectively. The estimated ceiling 
temperatures for the Hamedan, Malayer, and Isfahan varieties were $40.12,42$, and $35.57^{\circ} \mathrm{C}$, respectively. The biological times for $50 \%$ germination in the Hamedan, Malayer, and Isfahan varieties were estimated to be 165.5, 168.4 and 158.3 hours, respectively (Table 3).

Various reports have been published on the influence of temperature of seed germination in different crops, pastures, and medicinal plant species. Kamkar ${ }^{32}$ in their study on poppy, found its base, optimum and ceiling temperatures were $3.02,27.36$ and $36.31^{\circ} \mathrm{C}$, respectively. The research of Bannayan ${ }^{42}$ conducted on germination characteristics of a number of Iranian medicinal plants suggested their highest germination rates were achieved in the temperature ranges of 20$30^{\circ} \mathrm{C}$ for Punesa binaludi (Nepeta binaludensis) and Punesa Alborzi
(Nepeta crassifolia). The related ranges for Avishan-E-Shirazi (Zataria multiflora), catmints (Nepeta glomerulosa), and for Avishan ekuhi or kotschyam thyme (Thymus kotschyanus) and madder (Rubia tinctorum) and yarrow (Achillea millefolium ssp. elburensis) were $15-20,20-25$, and $15-30^{\circ} \mathrm{C}$, respectively. $\mathrm{Khalili}^{43}$ studied grain germination in barley and found the base, optimum, and ceiling temperatures were $-0.09,27.5$, and $35.7^{\circ} \mathrm{C}$, respectively. Zeinali ${ }^{44}$ studied grain germination in 12 wheat varieties and reported that the optimum temperatures grain germination varied from 31.8 to 32.4 , and ceiling temperatures ranged from 38.1 to $42.1^{\circ} \mathrm{C}$. Mwale ${ }^{27}$ studied sunflower varieties and found the temperature ranges of 1-5.1, 3436.7, and 45.5-50.9 as the base, optimum, and ceiling temperature ranges, respectively (Figure 3).

Table I Variance analysis of mean squares of maximum germination percentage (MGR), germination uniformity (GU), germination rate (GR), and time to $5 \%$ $\left(D_{5}\right), 10 \%\left(D_{10}\right), 50 \%\left(D_{50}\right), 90 \%\left(D_{90}\right)$ and $95 \%\left(D_{95}\right)$ germination based on fennel variety, temperature individual and combined

\begin{tabular}{|c|c|c|c|c|c|c|c|c|c|}
\hline Source of variation & DF & MGP & GU & GR & $\mathbf{D}_{5}$ & $D_{10}$ & $D_{50}$ & & $\mathbf{D}_{95}$ \\
\hline Variety & 2 & $54.88^{\text {n.s }}$ & $683.86^{\text {n.s }}$ & $0.000002^{\text {n.s }}$ & $1719.20^{\mathrm{ns}}$ & $1829.40^{\text {n.s }}$ & $3072.56^{\mathrm{n} . \mathrm{s}}$ & $4587.59^{n . s}$ & $4483.89^{n . s}$ \\
\hline Temperature & 5 & $21434.22^{* *}$ & $63067.03 * *$ & $0.00002 * *$ & $21640.96 * *$ & $17676.39 * *$ & $30203.55 * *$ & $80629.90 * *$ & $99879.36 * *$ \\
\hline Variety* Temperature & 10 & $15.08^{\text {n.s }}$ & $929.10^{\text {n.s }}$ & $0.000004^{\text {n.s }}$ & $2827.35^{\mathrm{n} . \mathrm{s}}$ & $2795.36^{\text {n.s }}$ & $2823.97^{\text {n.s }}$ & $3240.59^{\text {n.s }}$ & $3285.47^{\text {n.s }}$ \\
\hline Errors & 54 & 20.00 & 601.41 & 0.0000003 & 4125.43 & 4134.67 & 4310.07 & 4827.83 & 5008.11 \\
\hline
\end{tabular}

The symbols $* *$ and $*$ indicate significance at the $\mathrm{I}$ and 5 percent level of probability, respectively. Values of mean squares and those of $\mathrm{F}$ are used for error and for other sources, respectively.
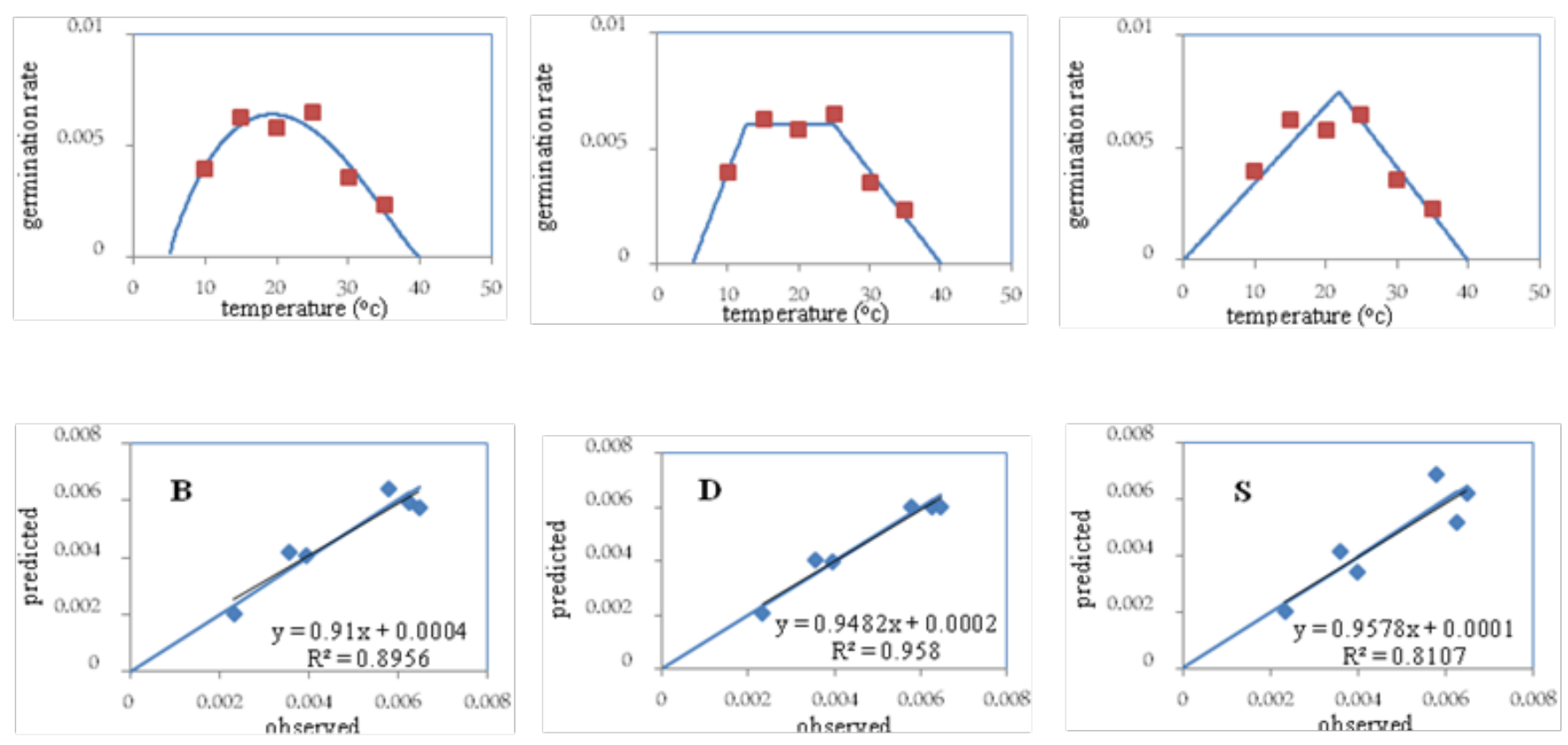

Figure I The relationship between seed germination speed and temperature $\left({ }^{\circ} \mathrm{C}\right)$, The predicted values for $50 \%$ germination obtained by using the beta $(\mathrm{B})$, the dent-like (D), and the segmented (S) functions are presented against the observed value in the Hamedan variety. 
Table 2 Root mean square of errors (RMSE), coefficient of variation (CV), coefficient of determination (R2) and coefficient of regression (a and b) quantified by beta, segmented and dent-like models used to determine effect of temperature on seed germination in three fennel varieties

\begin{tabular}{lllllll}
\hline Variety & Model & RMSE & CV & $\mathbf{R}^{2}$ & $\mathbf{a}$ & $\mathbf{b}$ \\
\hline Hamedan & Beta & 0.0004 & 13.95 & 0.98 & $0.0004^{\text {n.s }}$ & $0.91^{\text {n.s }}$ \\
& Segmented & 0.0007 & 15.41 & 0.97 & $0.0001^{\text {n.s }}$ & $0.95^{\text {n.s }}$ \\
& Dent-like & 0.0003 & 11.36 & 0.99 & $0.0002^{\text {n.s }}$ & $0.94^{\text {n.s }}$ \\
Malayer & Beta & 0.0004 & 7.65 & 0.99 & $0.0016^{\text {n.s }}$ & $0.69^{\text {n.s }}$ \\
& Segmented & 0.0018 & 28.83 & 0.93 & $-0.0020^{\text {n.s }}$ & $1.22^{\text {n.s }}$ \\
& Dent-like & 0.0002 & 5.34 & 0.99 & $0.0005^{\text {n.s }}$ & $0.90^{\text {n.s }}$ \\
Isfahan & Beta & 0.0006 & 10.25 & 0.98 & $0.0008^{\text {n.s }}$ & $0.85^{\text {n.s }}$ \\
& Segmented & 0.0013 & 21.01 & 0.94 & $0.0021^{*}$ & $0.57^{\text {n.s }}$ \\
& Dent-like & 0.0005 & 6.32 & 0.99 & $0.0004^{\text {n.s }}$ & $0.92^{\text {n.s }}$ \\
\hline
\end{tabular}

The symbols * and ** accompanying "a" show significant differences with zero, and in "b" significant differences with one
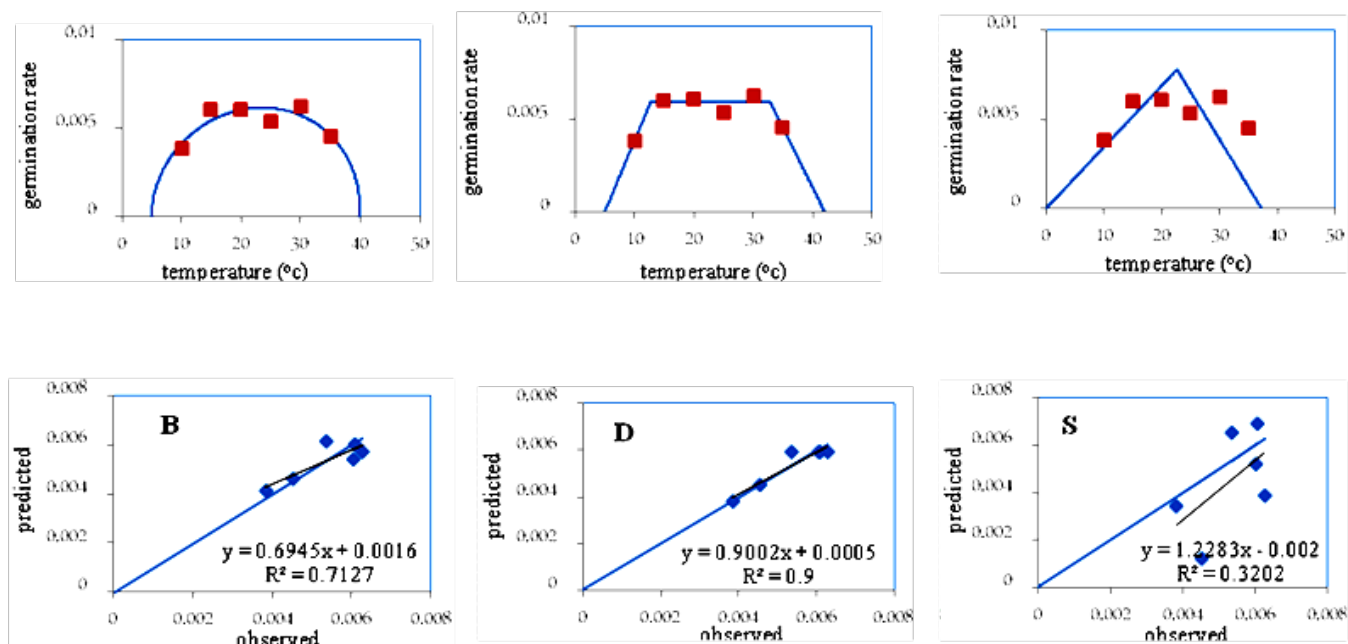

Figure 2 The relationship between seed germination speed and temperature $\left({ }^{\circ} \mathrm{C}\right)$, The predicted values for $50 \%$ germination obtained by using the beta $(\mathrm{B})$, the dent-like (D), and the segmented (S) functions are presented against the observed value in the Malayer variety.
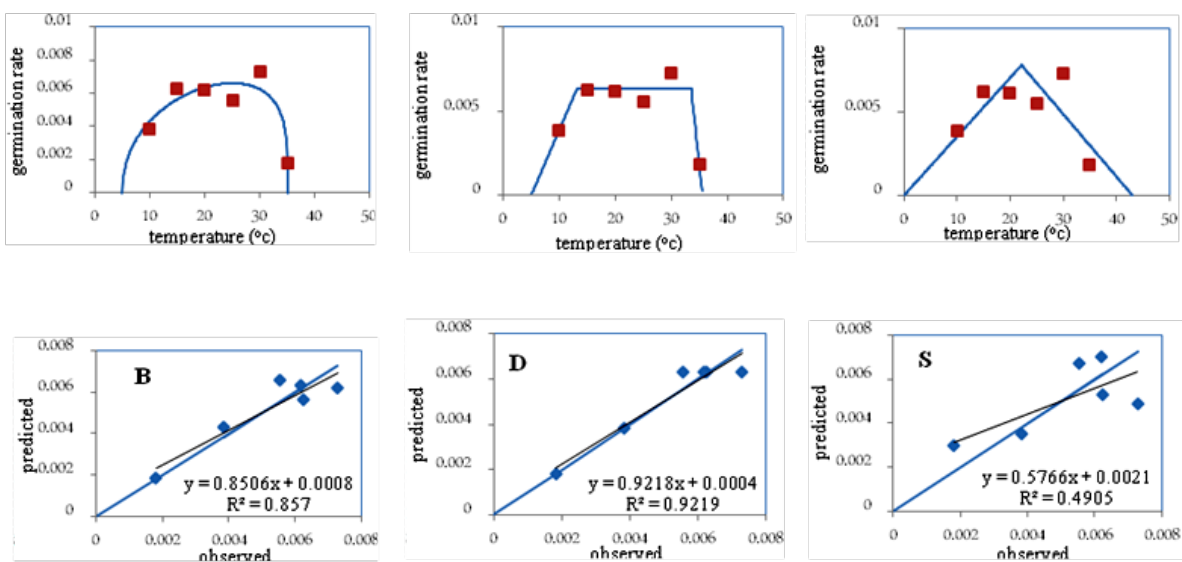

Figure 3 The relationship between germination speed and temperature $\left({ }^{\circ} \mathrm{C}\right)$, the predicted values for $50 \%$ germination obtained by using the beta $(\mathrm{B})$, the dent-like $(D)$, and the segmented $(S)$ functions are presented against the observed value in the Isfahan variety. 
Table 3 Estimation of base, optimum, lower limit, upper limit, ceiling temperatures and biological time of germination in three fennel varieties by beta, segmented and dent-like models

\begin{tabular}{|c|c|c|c|c|c|c|c|}
\hline Model & Variety & a & $T_{b}$ & $\mathrm{~T}_{01}$ & $\mathrm{~T}_{02}$ & $T_{c}$ & $F_{0}$ \\
\hline \multirow{3}{*}{ Beta } & Hamedan variety & 0.87 & 5 & - & 19.36 & 40 & 156.2 \\
\hline & Malayer variety & 0.5 & 5 & - & 23.57 & 40 & 162.1 \\
\hline & Isfahan variety & 0.45 & 5 & - & 25 & 35.01 & 151.5 \\
\hline \multirow{3}{*}{ Segmented } & Hamedan variety & - & 0.00000001 & - & 21.83 & 39.92 & 133.2 \\
\hline & Malayer variety & - & 0.00000001 & - & 22.63 & 37.24 & 127.9 \\
\hline & Isfahan variety & - & 0.00000001 & - & 22.15 & 43.06 & 127.9 \\
\hline \multirow{3}{*}{ Dent-like } & Hamedan variety & - & 5 & 12.53 & 25 & 40.12 & 165.5 \\
\hline & Malayer variety & - & 5 & 12.75 & 32.81 & 42 & 168.4 \\
\hline & Isfahan variety & - & 5 & 13.45 & 33.56 & 35.57 & 158.3 \\
\hline
\end{tabular}

(a) constant coefficient for beta, (Tb) base temperature, (To) optimum temperature, (Tol) lower limit of optimum temperature, (To2) upper limit of optimum temperature, (Tc) ceiling temperature and (Fo) biological time.

\section{Conclusion}

In general, results of this research suggest that, among the common non-linear regression models that are used for quantifying the effects of temperature on germination (the beta, dent-like, and segmented models), the dent-like model fitted best to the observed data for the three tested varieties of Hamedan, Malayer, and Isfahan. Therefore, it was chosen as the superior model and was used to determine the cardinal temperatures of germination (the base, the lower limit of optimum, the upper limit of optimum, and the ceiling temperatures). This model, compared to the other two, enjoys greater accuracy in describing germination rate of this plant against temperature and can describe the relationship between germination rate and temperature in this plant well. Given these results, the proposed model can be used for quantification of germination responses of fennel, and for creating models for predicting the time of its germination and emergence. Moreover, our results showed that this plant enjoys a wide desirable range, and this can be a promising characteristic for fennel to adapt itself well and be grown in various regions, and even at different planting dates. The important point is that the response of this plant to temperature at other stages of growth must also be studied. These parameters are applicable where soil moisture is not a limiting factor in germination; otherwise, the effects of soil moisture must also be calculated and used as a correction factor in calculating biological time.

\section{Acknowledgements}

None.

\section{Conflict of interest}

The author declares no conflict of interest.

\section{References}

1. Omidbaigi R. Production and Processing Strategies for Medicinal
Plants. Volume 2, 1st ed. Tehran, Iran: Tarrahan-e-Nashr Publications; 1997. 424 p (In Farsi).

2. Kandil MA. The effect of fertilizers for conventional and organic farming on yield and oil quality of fennel (Foeniculum vulgare) in Egypt. Europe, Germany: Federal Agricultural Research Centre; 2002. 74 p.

3. Malhotra SK. Fennel and fennel seed. In: Peter KV editor. Handbook of Herbs and Spices. 2nd ed. Volume 2, UK: A volume in Woodhead Publishing Series in Food Science, Technology and Nutrition; 2012. p. 275-302.

4. Ghaderi-Far F, Soltani A, Sadeghipour HR. Evaluation of nonlinear regression models in quantifying germination rate of medicinal pumpkin (Cucurbita pepo L. subsp. Pepo. Convar:Pepo var. styriaca Gerb), borago (Borago officinalis L.) and black cumin (Nigella sativa L.) to temperature. J Agric Sci Natur Resour. 2009;6(4):1-20 (In Farsi).

5. Lee MH. Low temperature tolerance in rice:the Korean experience. In:Fukai S \& Basnayake J (Eds.), increased lowland Rice in the Mekong Region. ACIAR proceedings. 2001;101:109-117.

6. Shafii B, Price WJ. Estimation of cardinal temperatures in germination data analysis. J Agric Bio Environ Statis. 2001;6(3):356-366.

7. Rajasekaran LR, Stiles A, Caldwell CD. Stand establishment in processing carrots-Effects of various temperature regimes on germination and the role of salicylates in promoting germination at low temperatures. Can J Plant Sci. 2002;82(2):443-450.

8. Windauer L, Altuna A, Arnold BR. Hydrotime analysis of Lesquerella fendleriseed germination responses to priming treatments. Ind Crop Prod. 2007;25(1):70-74.

9. Kamkar B, Ahmadi M, Soltani A, et al. Evaluating non-linear regression models to describe response of wheat emergence rate to temperature. Seed Sci Technol. 2008;2:53-57.

10. Bewley JD, Black M. Seeds: physiology of Development and Germination. 2nd ed. New York, USA: Plenum press; 1994.

11. Bradford KJ. A water relation analysis of seed germination rates. Plant Physiol. 1990;94(2):840-849. 
12. Brodford KJ. Applications of hydrothermal time to quantifying and modeling seed germination and dormancy. Weed Sci. 2002;50(2):248260.

13. Larsen SU, Bailly C, Come D, et al. Use of the hydrothermal time model to analysis interacting effects of water and temperature on germination of 3 grass species. Seed Sci Res. 2004;14(1):35-50.

14. Baskin C, Baskin JM. Seeds: ecology, biogeography, and evolution of dormancy and germination. San Diego, California, USA: Academic press; 2001. $666 \mathrm{p}$.

15. Alvarado V, Bradford KJ. A hydrothermal time model explains the cardinal temperatures for seed germination. Plant Cell Environ. 2002;25(8):1061-1069.

16. Ramin AA. The influence of temperature on germination taree irani. Seed Sci Technol. 1997;25(3):419-426.

17. Bewley JD. Seed germination and dormancy. Plant Cell. 1997;9(7):1055-1066.

18. Kebreab E, Murdoch AJ. The effect of water stress on the temperature range for germination of Orobanches aegyptiacaseeds. Seed Sci Res. 2000;10(2):127-133.

19. Soltani A, Robertson MJ, Torabi B, et al. Modeling seedling emergence in chickpea as influenced by temperature and sowing depth. Agr For Meteorol. 2006;138(1-4):156-167.

20. Ellis RH, Roberts EH. The quantification of aging and survival in orthodox seeds. Seed Sci Technol. 1981;9(2):373-409.

21. Hejazi A. Seed Technology. Iran, (In Farsi): Tehran University Publications; 1994.

22. Copeland LO, McDonald MB. Principles of Seed Science and Technology. USA: Publication Chapman and Hall; 1999.

23. Iannucci A, Di Fonzo N, Martiniello P. Temperature requirements for seed germination in four annual clovers grown under two irrigation treatments. Seed Sci Technol. 2000;28(1):59-66.

24. Al-Ahmadi MJ, Kafi M. Cardinal temperatures for germination of Kochia scoparia(L). J Arid Environ. 2007;68(2):308-314.

25. Kebreab E, Murdoch AJ. A model of the effects of a wide range of constant and alternating temperatures on seed germination of four Orobanchespecies. Ann Bot. 1999;84(4):549-557.

26. Jordan GL, Haferkamp MR. Temperature responses and calculated heat units for germination of several range grasses and shrubs. $J$ Range Manag. 1989;42(1):41-45.

27. Mwale SS, Azam-Ali SN, Clark JA, et al. Effect of temperature on the germination of sunflower. Seed Sci Technol. 1994;22(3):565-571.

28. Ellis RH, Covell S, Roberts EH, et al. The influence of temperature on seed germination rate in grain legumes. II. Intraspecific variation in chickpea (Cicer arietinumL.) at constant temperatures. J Exp Bot. 1986;37(10):1503-1515.

29. Jame YW, Cutforth HW. Simulating the effects of temperature and seeding depth on germination and emergence of spring wheat. Agr For Meteorol. 2004;124(3-4):207-218.
30. Hardegree SP. Predicting germination response to temperature. I. Cardinal temperature models and subpopulation-specific regression. Ann Bot. 2006;97(6):1115-1125.

31. Ghaderi-Far F, Galeshi S, Sadati SJ, et al. Determination of cardinal temperature in Trifolium aubterraneum L. Pajouhesh and Sazandegi. 2001;53:36-39 (In Farsi).

32. Kamkar B, Jami Al-Ahmadi M, Mahdavi Damghani A, et al. Quantification of the cardinal temperatures and thermal time requirement of opium poppy (Papaver somniferum L.) seeds to germinate using nonlinear regression models. Ind Crop Prod. 2012;35(1):192-198.

33. Kamkar B, Koocheki AR, Mahallati MN, et al. Cardinal temperature for germination in three millet species (Panicum miliaceum, Pennisetum glaucumand Setaria italica). Asian J Plant Sci. 2006;5(2):316-319.

34. Nozari-nejad M, Zeinali E, Soltani A, et al. Quantify wheat germination rate response to temperature and water potential. Elect J Crop Prod. 2013;6(4):117-135 (In Farsi).

35. Kamkar B. GS 2011. A pocket software to calculate germination and emergence indices. GUASNR; 2011

36. Piper EL, Boote KJ, Jones JW, et al. Comparison of two Phenology models for predicting Flowering and maturity date of soybean. Crop Sci. 1996;36(6):1606-1614.

37. Ritchie JT, NeSmith DS. Temperature and crop development. In: Hanks RJ, et al. editors. Modeling Plant and Soil Systems. Agronomy Monograph No. 31, USA: American Society of Agronomy; 1991. p. 5-29.

38. Soltani A. Application of SAS in statistical analysis. Mashhad, Iran: Jihad-daneshgahi Press; 2007. 180 p.

39. Ahmadi M, Kamkar B, Soltani A, et al. Evaluation of non-Linear regression models to predict stem elongation rate of wheat (Tajan cultivar) in response to temperature and Photoperiod. Elect J Crop Prod. 2010;2(4):39-54 (In Farsi).

40. Kamaha C, Magure YD. Effect of temperature on germination of 6 winter wheat cultivars. Seed Sci Technol. 1992;20(1):181-185.

41. Thygerson T, Harris JM, Smith BN, et al. Metabolic response to temperature for six populations of winter fat (Eurotia lanata). Thermochimica Acta. 2002;394(1-2):211-217.

42. Bannayan AM, Nadjafi F, Rastgoo M, et al. Germination properties of some wild medicinal plants from Iran. Seed Technol. 2006;28(1):80-86.

43. Khalili N. Predicting barley (Hordeum vulgare L.) emergence as affected by temperature, moisture and sowing depth. M.Sc. Thesis, Gorgan, Iran: Univer Agric Sci Natur Resour; 2013. 60 p.

44. Zeinali E, Soltani A, Galeshi S, et al. Cardinal temperatures, response to temperature and range of thermal tolerance for seed germination in wheat (Triticum aestivum L.) cultivars. Elect J Crop Prod. 2010;3(3):23-42. 